\title{
Rastros del acoso en la piel
}

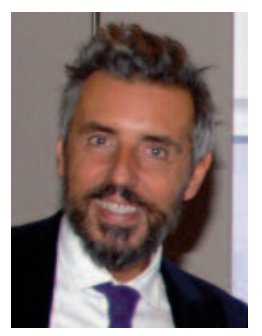

Raúl de Lucas Laguna Jefe de la Sección de Dermatología Pediátrica. Hospital Universitario La Paz. Madrid.
Cuando un dermatólogo ve en la piel de un paciente lesiones que no se adaptan a los patrones típicos de distribución de las dermatosis más habituales, saltan las alarmas: podemos encontrarnos ante una dermatosis facticia o artefacta o, peor, que estas lesiones sean la manifestación del maltrato. Esta situación es aún más dramática, si cabe, si nuestro paciente es un niño. La cuestión es la siguiente: ¿debemos estar preparados para identificar esta situación?, ¿cuándo debemos sospechar?, ¿han pensado que una dermatosis artefacta puede esconder un abuso o maltrato?, ¿qué debemos hacer ante una sospecha de maltrato? Pues bien, si esto les interesa, sigan leyendo.

Nuestra directora, la Dra. Aurora Guerra-Tapia, escribió hace unos años en el periódico El Mundo (www.elmundo.es/salud/2000/415/ 977936104.html): «Cuando un niño se encuentra inadaptado en el colegio o fracasa en sus estudios, cuando un adolescente se siente desconcertado al comenzar su pubertad, o cuando a un adulto le va mal en su vida familiar o laboral, esto es, cuando un ser humano tiene problemas, a veces su única forma de pedir ayuda es lesionarse la piel», y es que incluso una dermatosis artefacta puede esconder una historia personal de abusos o maltrato, como así lo demuestran algunos estudios ${ }^{1,2}$, en los que se señala que esta forma de dermatosis autoprovocada puede ser una de las manifestaciones tardías del abuso sexual.

En la consulta de dermatología y en el ejercicio de la medicina en general, debemos estar alerta para identificar varios tipos de abuso, muchos de ellos con manifestaciones directas o indirectas en la piel; me refiero al abuso físico, sexual, emocional, o a la negligencia en caso de que nuestros pacientes sean personas dependientes o niños.

En lo que respecta a las infecciones de transmisión sexual (ITS), en el trabajo de Rodríguez-Pichardo y García-Bravo ${ }^{3}$, se analizan las ITS en la infancia y en la adolescencia, circunstancias que nos deben hacer descartar, en primer lugar, el abuso sexual como causa de estas en algunos pacientes y, por supuesto, en todos los menores de 16 años, como marca la ley española ${ }^{4}$. En el estudio de Rodríguez-Pichardo y GarcíaBravo, se expone que el $75 \%$ de las personas objeto de abuso son niñas y que, en nuestro medio, el $1 \%$ de las niñas han sufrido algún tipo de abuso sexual, siendo las edades de entre los 7 y los 13 años las de mayor vulnerabilidad. Según los datos, en el $90 \%$ de los casos probados de abuso sexual hubo penetración, oral en niños y anal en niñas; sin duda, hay factores sociales como la pobreza, la exclusión social, las adicciones y la historia de malos tratos en pareja que favorecen la aparición de esta terrible realidad. Los dermatólogos, 
por lo tanto, tenemos la oportunidad - $-\mathrm{y}$, tal vez, la obligación- de sacar a la luz estas circunstancias.

En una reciente revisión, se comunican datos aún más preocupantes ${ }^{5}$ : una gran proporción de niños con ITS después del período neonatal, mucho más de lo tradicionalmente estimado, han sufrido abuso sexual. Se informa también de que, al menos, el 31-58\% de los niños de 14 años o menos con verrugas anogenitales han sufrido abuso sexual, demostrándose que los tipos de virus del papiloma humano genital se encuentran significativamente con más frecuencia en los casos de abuso sexual probado, probable y posible que en niños sin ninguna sospecha de abuso sexual.

Con respecto a otras ITS como la sífilis y la gonococia, sabemos bien que son sinónimo de abuso seguro cuando aparecen en la infancia, pero la infección oftálmica con Neisseria gonorrhoeae en mayores de 1 año o de Chlamydia trachomatis en mayores de 3 años puede indicar abuso sexual.

Podemos encontrarnos también con lesiones cutáneas que directamente nos sugieran un maltrato directo; me refiero a cortes, laceraciones, equimosis, quemaduras, etc. Nuestra propia intuición, el análisis de otros datos (sociales, psicológicos, etc.) harán posible una vez más «destapar» estas situaciones. Es razonable comentar que muchas veces no estamos preparados para ver la realidad porque esta es dura, cruel y, por qué no, incómoda. Informar de nuestra sospecha a unos padres o cuidadores puede suponer un estrés que, a veces, es difícil de soportar; sin embargo, debemos ser conscientes de que "la víctima» depende de nosotros más de lo que nosotros mismos creemos para salir de ese «infierno». Teniendo en cuenta que un $90 \%$ de los niños maltratados tienen lesiones cutáneas ${ }^{6}$ (quemaduras, hematomas, erosiones, ampollas, trazos lineales, laceraciones, mordeduras) y, sin embargo, solo en el $5 \%$ de los casos de abuso sexual hay lesiones cutáneas (pues los tocamientos o las agresiones a través de internet no dejan lesiones en la piel, pero sí en la mente), considero que estamos obligados a informar a las autoridades de nuestras sospechas. No debemos olvidar que a veces dermatosis frecuentes como, por ejemplo, la dermatitis del pañal (fig. 1) pueden esconder negligencia, abandono o dejación de cuidados, que no es más que la forma más cruel de maltrato cuando es un bebé o un anciano la víctima; el análisis de otros datos físicos (falta de higiene, desnutrición, etc.), de nuevo, nos ayudará a diagnosticar.

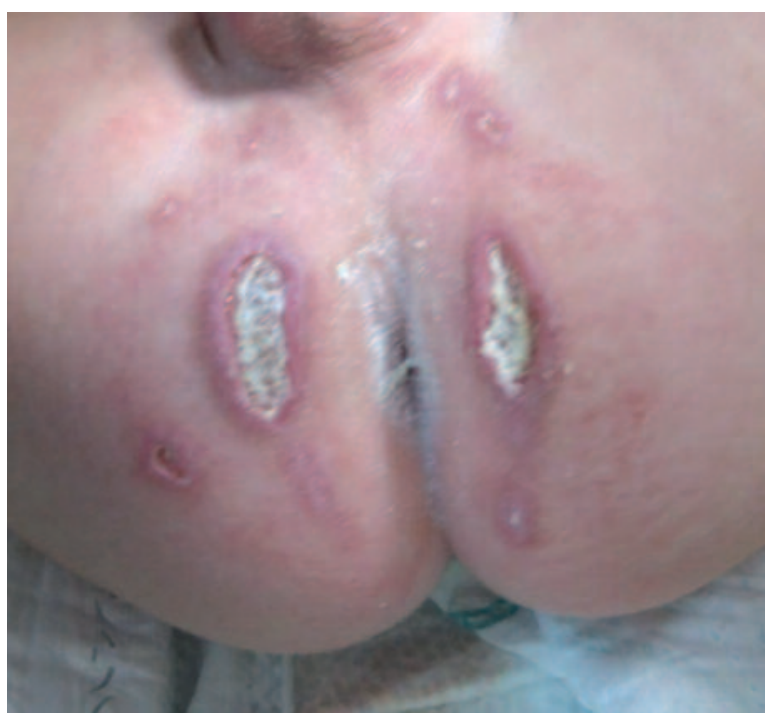

Figura 1. En ocasiones una dermatitis del pañal de evolución tórpida puede ser indicativa de maltrato, en este caso por omisión de cuidados.

En general, la familia es la que sospecha el abuso o maltrato en la mayoría de los casos, seguidos por nosotros, los profesionales; la sospecha arranca la mayoría de las veces a partir del relato del niño y, en segundo lugar, por indicios físicos ${ }^{7}$, frecuentemente localizados estos en la piel o en mucosas. Con respecto al abusador o maltratador, en el caso de menores, en el $30 \%$ de las ocasiones es el padre o un familiar cercano; el «retrato robot» de un maltratador sería el siguiente: varón, de más de 35 años, profesional cualificado, de nivel social medio o alto, «cariñoso» con los niños y cercano a la familia de la víctima; suelen tener un trabajo relacionado con la infancia y, en general, mantienen buena conducta en prisión (no hay niños), 
siendo su reincidencia muy alta una vez que salen de la cárcel.

Ante una sospecha de abuso sexual infantil o maltrato, como médicos, debemos informar a la autoridad a través de una notificación al juzgado de menores en estas circunstancias:

- Si aporta denuncia previa, tenga o no lesiones.

- Ante la evidencia de lesiones moderadas o graves sugestivas de abuso sexual, refiera o no la agresión.

- Ante la convicción de que existió realmente abuso sexual o un relato creíble, tenga o no lesiones.

- Si requiere protección inmediata: enviar por fax (o teléfono) al juez de guardia.

Para finalizar, quiero señalar la importancia que tenemos como dermatólogos en la sospecha, cribado y comunicación de cualquier presunción de abuso sexual en niños o adultos. No debemos quedarnos solo en indicios físicos, que pueden explicarse por otros motivos, sino que debemos observar lo que acompaña al paciente, su situa- ción familiar, social y mental, pues la clave muchas veces está en la suma de todos estos aspectos.

En pocas palabras, ante una sospecha de abuso sexual o maltrato infantil: observar, pensar, sospechar, estudiar, informar y notificar y, por supuesto, «tolerancia cero».

\section{BIBLIOGRAFÍA}

1. Gupta MA, Gupta AK. Dermatitis artefacta and sexual abuse. Int J Dermatol. 1993;32(11):825-6.

2. Harth W, Linse R. Dermatological symptoms and sexual abuse: a review and case reports. J Eur Acad Dermatol Venereol. 2000;14(6):489-94.

3. Rodríguez-Pichardo A, García-Bravo B. Infecciones de transmisión sexual en la infancia y la adolescencia. Piel. 2005;20(7): 331-7.

4. Ley Orgánica 10/1995, de 23 de noviembre, del Código Penal. Artículo 181.1., Capítulo II («De los abusos sexuales»), Título VIII («Delitos contra la libertad e indemnidad sexuales»), Libro II («Delitos y sus penas»). BOE. 1995;(281):34009.

5. Rogstad KE, Wilkinson D, Robinson A. Sexually transmitted infections in children as a marker of child sexual abuse and direction of future research. Curr Opin Infect Dis. 2016;29(1): 41-4.

6. Pau-Charles I, Darwich-Soliva E, Grimalt R. Signos cutáneos del maltrato infantil. Actas Dermosifiliogr. 2012;103(2):94-9.

7. Pou Fernández J, Ruiz España A, Comas Masmitjá LI, Petitbó Rafat MD, Ibáñez Fanes M, Bassets Marill J. Abuso sexual. Experiencia en una unidad funcional de abusos a menores. An Esp Pediatr. 2001;54:243-50. 